\title{
Socioecological Approaches for Combining Ecosystem-Based and Customary Management in Oceania
}

\author{
Shankar Aswani \\ Department of Anthropology and IGP Marine Science, University of California, Santa Barbara, CA 93106-3210, USA \\ Correspondence should be addressed to Shankar Aswani, aswani@anth.ucsb.edu
}

Received 19 June 2010; Accepted 5 October 2010

Academic Editor: Robert J. Toonen

Copyright () 2011 Shankar Aswani. This is an open access article distributed under the Creative Commons Attribution License, which permits unrestricted use, distribution, and reproduction in any medium, provided the original work is properly cited.

This paper summarizes various integrated methodological approaches for studying Customary Management for the purpose of designing hybrid CM-Ecosystem-Based Management (EBM) systems in Oceania. Using marine conservation in the Western Solomon Islands as an example, the paper illustrates various interdisciplinary human ecological methods that can assist in designing hybrid conservation programs. The study of human-environmental interactions from a socio-ecological perspective allows us to discern people's understanding of their immediate environment, differential forms of local resource governance and use (e.g., sea tenure and foraging strategies), and existing conflicts between various stakeholders, among other social and ecological factors. More generally, the paper shows how coupled studies of natural and social processes can foster management regimes that are more adaptive and effective and that move toward holistic, ecosystem-based marine conservation in the Pacific Island region.

\section{Introduction}

Today, ecosystem-based management (EBM) is emerging as a leading approach for fisheries and coastal zone management around the world [1-3]. Essentially, EBM is the management of a particular ecosystem's structure, function, and processes to sustain and foster ecosystem services for human society, and, therefore, it focuses on the interconnectedness of ecological, social, and economic parameters for developing place-based management plans of an ecosystem [4]. For all its potential, however, EBM has been hardly ever implemented successfully because numerous problems can arise from competing interests among stakeholders, undeveloped or inappropriate governance structures, poor science, or lack of political will $[5,6]$. Government-sponsored EBM plans tend to focus on protecting biodiversity and ecosystem function, which, while they are important for sustaining and fostering ecological services $[7,8]$, are not a major concern in many Pacific Island nations. Furthermore, local governments and stakeholders are not too receptive to government-sanctioned schemes that disregard local governance institutions and practices [9], particularly members of customary management systems that are still prevalent in many parts of Oceania.
Customary governance and management (CM) systems are cultural and historical practices designed to regulate the use of, access to, and transfer of resources locally, and they are informed by indigenous ecological knowledge and embedded in customary land- and sea-tenure institutions [10, page 202]. It is important to note that CM system are not designed for conserving marine or terrestrial resources but, rather, for controlling access to and use of natural resources. In addition community-based management regimes designed around $\mathrm{CM}$ are often vulnerable to internal community dynamics, and, therefore, biological and social success in resource management is always conditional and susceptible to failure. In the case of the Pacific Islands, simply, given the lack of government resources for coastal management (e.g., policing, monitoring), there is no viable alternative to comanagement or community-based management.

In places where forms of customary management already exist and are functional, the question becomes as follows. Why should EBM be implemented? The answer is that while the origins of EBM and customary management are different-one being created from scientific managerialism and the other from adaptive socio-ecological and historical processes - their conceptual and operational principles intersect in many ways, which creates an opportunity 
for their cross-fertilization. The objective, therefore, is to work with existing frameworks and not to replace them, although this creates a new series of challenges, problems, and opportunities for the hybridization of EBM with local governance and management frameworks. To achieve this in the Pacific Islands, we need to study various socioecological dimensions of human-environmental relationships that characterize customary management systems in the region, and this necessitates the use of interdisciplinary natural and social science methods. Researches, however, rarely spell out the actual approaches and methods used in their socio-ecological research and how such hybridization between forms of management is even possible.

In this paper, using marine conservation as an example, I summarize various integrated methodological approaches for studying CM for the purpose of designing hybrid CMEBM systems in Oceania. I draw from my own scientific and applied work in the New Georgia Group in the Western Solomon Islands to illustrate various interdisciplinary human ecological methods that can assist in designing hybrid conservation programs. The study of human-environmental interactions from a socio-ecological perspective allows us to discern people's understanding of their immediate environment, differential forms of local resource governance and use (e.g., sea tenure and foraging strategies), and existing conflicts between various stakeholders, among other social and ecological factors. The paper also discusses how hybrid management systems can result in comprehensive conservation and management programs that while not always successful socially and biologically are better tailored to the local context. Practically speaking, such hybrid programs that operate at local scales $[11,12]$ are likely to be more successful than top-down, state-sponsored EBM plans, particularly in regions like Oceania in which local stakeholders retain a large measure of control over their natural resources.

\section{Socio-Ecological Approaches for Designing Hybrid EBM and CM Systems}

Most of the approaches illustrated in this paper were originally utilized to understand various dimensions of human-environmental relationships in the Solomon Islands, and the research involved over one hundred months of cumulative fieldwork by the author and his team members between 1992 and 2010. These human-ecological studies used a combination of qualitative and quantitative methods (a mix of ethnographic, geographic, economic, and marine science research methods) to delineate the dynamics of common property institutions and various facets of indigenous ecological knowledge and associated resource exploitation strategies. The research results were used to design a marine protected area (MPA) network in the Western Solomon Islands-MPAs being a primary tool of EBM-that now extends to cover more than six thousand hectares of diverse marine habitats in more than 32 MPAs (see [13]). The outlined approaches are fundamental to understanding human-environmental interactions, and, therefore, they are key to the development of hybrid EBM and CM programs for safeguarding marine biodiversity and ecological function in a culturally and socioeconomically compressive fashion. For this to happen, however, there are several components of $\mathrm{CM}$ that need to be disentangled and studied independently. Indeed there are also a number of components in EBM that need disentangling, but these are not presented in this paper.

2.1. Studying Customary Sea Tenure. Marine territoriality in Oceania, or customary sea tenure (CST), is a situation in which particular users have exclusive rights over resources and the ability to exclude nonmembers from accessing and using them. Tenure rights are distinguished through a number of sociocultural rules based on birth (primary rights), marriage and residence (secondary rights), and the direct transfer of rights by traditional authorities (usufruct rights) [14]. Indigenous entitlements allow users access to a benefit stream while excluding nonmembers. Research on Oceania's customary sea tenure includes cases from Polynesia (e.g., [15]), Micronesia (e.g., [16]), and Melanesia (e.g., [17]). Rights to sea space are not only characterized by control of geographical areas but can also entail rights to specific habitats, technologies, and species or a combination of these. Research has shown that these indigenous institutions are diverse and dynamic and that they have emerged from the amalgamation of traditional and imported practices [18]. Furthermore, these systems are more widespread than people actually recognize in the AsiaPacific region, as recent research shows that these not only survive in Oceania but also across Southeast Asia [19]. Key to this discussion is that exclusive rights allow stakeholders to potentially institute access and use restrictions, fishing gear restrictions, minimum size and catch limits, and to protect breeding aggregations and establish temporal or permanent marine closures-strategies that are at the core of EBM. Next, I illustrate research that is important to understanding CST prior to the hybridization with other management strategies.

2.1.1. Sea Tenure: EthnoHistory, Genealogical Demography, and Settlement Patterns. Studies have found that the institutional strength of marine tenure is related to a number of socioeconomic factors, including marine resource dependency, distance to markets, and settlement patterns among others $[20,21]$; factors that are often shaped by internal and external historical processes. History, therefore, matters when designing conservation programs that incorporate local governance institutions into management plans such as community-based management or EBM. For example, in the Roviana and Vonavona Lagoons, Western Solomons, a major basis for current governance differences between local communities lies in the history of regional patterns of settlement and demographic processes, as well as the way these interplay with the political economy to shape current territorial right claims and counterclaims. This kind of institutional variation, which can also be found in other areas of the region such as Papua New Guinea and Vanuatu $[21,22]$, raises a number of important questions. Do differences in governance and management practices exist 
among local communities? And what effects do historical demographic, economic, and political changes have on the organizational structure and managerial outcomes of common property regimes today? Researchers can use a combination of ethnohistorical, genealogical demographic, and microeconomic methods to answer these questions.

An initial step in ethnohistorical research is to determine the research population through a household census (either attained from government sources or independently by the researcher), followed by the design of a probability or nonprobability sampling strategy, which depends on the scope and nature of the research. A household questionnaire can be initially conducted across randomly selected households at each targeted village. Variables that can be included in the questionnaire include basic census data as well as questions on labour history, household income, household expenditures, rough estimates of task and time allocation to productive activities, commonly exploited commercial marine resources, asset ownership, and a series of other important issues that place the research population into a socioeconomic context. For an understanding of tenure regimes and their historical context, open and semistructured interviews can be conducted with household heads to explore in-depth, kinship, tribal history, marine territoriality, and particularly people's current perceptions of resource use and access rules and their actual behaviour within each tribal territory (i.e., tenure regime). For more indepth ethnohistorical research, household heads interviewed during the census and questionnaires can be asked to identify key informants (or a snowball sample). Once identified, these informants can be interviewed with in-depth, open-ended, semistructured and structured interviews on regional oral history. Researchers can then cross-reference the oral history with existing archaeological and historical records to better understand the historical processes that have impinged upon current territorial configurations.

In the Western Solomon Islands, for instance, this information was important for designing hybrid management programs in the region because the household questionnaires and the oral history interviews provided (1) a qualitative review of historical settlement patterns and the identification of different forms of sea tenure in the region and (2) a quantitative measure of the geographical distribution of households having members with tribal affiliations to the major estates of the region. A simple chi-square, which was employed to analyze the distribution of households with at least one member belonging to the major estates, showed that the observed association between contemporary villages and existing tribal affiliations is significantly nonrandom. The results illustrated how peoples' asymmetric regional settlement patterns in the recent past have influenced their current capacity to institute cooperation and enforcement mechanisms communally today. Clearly, such an understanding is crucial when combining strategies such as CM and EBM for managing marine resources.

Studies in Papua New Guinea have shown the utility of reconstructing patterns of population increases over a period of one century using genealogical information [23]. Historical demographic processes have significant impacts on the social institutions that embed indigenous common property regimes such as CST. While there are a number of sophisticated approaches for reconstructing demographic trajectories, there are simple methods that can be used in nonliterate societies or where government data are missing (which is common in many areas of Melanesia) to gauge population trends over the last one hundred years. First, one needs to collect recent demographic data on general regional trends such as fertility, mortality, and population growth from the government (when data are available) and through a census (embedded in the household questionnaire) to gauge the possible effects of demographic changes on resource-management strategies. Simple methods like family mapping and spatial patterns of settlement can be used to further fine-tune information on population trends within an identified CST system in the region.

Family mapping is used to identify main family trees for sampling within selected villages of each sea-tenure territory, starting with the parents of the older living members of a community [24]. Once the main lineages have been identified, members of each family are asked to identify all children born (dead and alive) to each person in each generation beginning with the parents of the older living generation. Because older people find it hard to remember accurate dates, significant historical markers can be used to help people's memory, including WWII (1940s), the coming of development projects such as logging (1960s-1980s), and the new millennium (2000s). Next, informants can be asked to identify all old and new settlements established over the informant's life span to determine changes in spatial settlement patterns for villages within each territorial estate. Old people who have resided at a settlement for 75 years or more are asked to identify new settlements across three points in their lifetime (youth, maturity, old age). To allow for variation in settlement size, informants are asked to rank settlements according to a rough estimate of population size (e.g., single family, extended family, village, and so forth). Afterward, the average distance between settlements at the three temporal points are measured and plotted in a set of aerial photographs. Naturally, all this information can be georectified and imported into a GIS according to the estimated year of establishment to furnish coarse measures of population density change patterns over the last century. For example, in our Western Solomons research, these two approaches have allowed us to identify population trends within each sea-tenure regime and to extrapolate the possible effects of population growth on the spatial distribution of stakeholders, and consequently on their territorial strategies.

\subsubsection{Sea Tenure: Socioeconomic Transformations and Coping Strategies. Data on demographic and spatial settlement pattern changes need to be combined with current economic activities and changing consumer demands to identify the institutional responses of each regional sea-tenure regime to current socioeconomic changes. Does an open-access common emerge from the breakdown of local institutions caused by transforming consumer demands, the market economy, and population growth? In the Western Solomons}


research, the economic behaviour of lagoon dwellers was investigated to determine the vulnerability and/or stability of indigenous sea-tenure institutions to changing consumer demands and to the encroachment of the market economy. For instance, in the Western Solomon program I recorded existing economic and livelihood differences between villages across sampling years 1994-1995, 1998-2003, and 2009 to explain the relationship between economic inequality and control of marine resources in the region. Various methods, including income and expenditure analysis, time-allocation studies, food diaries, and structured interviews, were used to understand people's livelihoods and food security and to measure their responses to changing economic conditions. These results, in turn, allowed for the design of MPAs that were sensitive to local coping strategies.

Understanding income and expenditure patterns is important for establishing each household's participation in the market economy. There are a number of methods to record this information, but for attaining a larger sample size, a diary method is best suited. A first step is to improve the survey instrument by conducting a pilot study, so that when applied, the survey schedule can be easily comprehended and completed by the selected members of each sampled household. For example, in the Solomon Islands research, I sampled households in targeted villages that had been identified by censuses conducted in 1994 and 2001. I selected members of randomly selected households (at least $50 \%$ of households across 15 villages) to keep a record of all economic activities for a week. The income schedule included questions ranging from day of transaction and goods sold to the member selling the product and the contribution to income by each gender. The expenditure schedules were formulated in a similar fashion. Several cycles were conducted to allow for a representative sample within the framework of seasonal variation in economic activities, particularly those concerned with marine resource exploitation. Data were compared across sampling years to examine recent developments and identify any economic and institutional changes associated with sea-tenure regimes. Understanding household income and expenditure and coping strategies is important because, as shown by Evans et al. [25] in Eastern Indonesia, a drop in market price for cash crops can negatively affect household well-being and, in turn, engagement in customary management strategies [10].

Showing how people use time is important for understanding the ways in which households meet their subsistence and economic needs. Time-allocation studies centre on people's use of time and their various productive modes. Analyzing time budgets provides a measure of daily activities in an objectively generated way, without having to rely on vague descriptions of behaviour gathered through interviewing alone. General trends in time allocation to productive activities can be extrapolated from household questionnaires, albeit more accurate methods of observation can be used. The spot check method, for instance, consists of randomly selecting times and dates to visit households and to record household members' activities as soon as they are observed [26]. Activities of absent members are recorded by asking present individuals. Then, the proportion of observations for each behaviour is calculated by dividing the number of observations for any given activities by the total number of spot check observations (for all activities). In the Western Solomons case, familiarity with local modes of production in the region allowed for informed coding of the activity categories. Randomness and generality were maintained by sampling behaviours throughout the year by local research assistants. These measurements helped to (1) discern regional differences in the use of time for income-productive activities in comparison with subsistence ones, (2) examine seasonal interregional shifting patterns of resource use, and most importantly, (3) examine timeuse differentiation across the identified sea-tenure regimes and its relation to changing consumer demands and fishery commercial activities. Note that time allocation studies can be complicated and time consuming, and alternative methods such as ordinal ranking of productive activities can be used (e.g., [27]).

Finally, researchers can use interviewing and food diary methods to examine issues of household food security in different target communities. Structured interviews for understanding food security can complement other methods detailed in this paper by exploring (1) the number of meals prepared daily, (2) dietary diversity, (3) incidence of food shortage, (4) coping strategies for insufficient food, and (5) perceptions of food security and adequacy. In the Western Solomons research, I collected these data using a Likertscale questionnaire design. In addition, food diaries were used to quantify actual household food intake. A member of the household was asked to keep a record for a week of all meals and food per meal consumed by each member. Data (food diaries and kitchen forms) were compared in order to determine if differences existed between sampling years and villages and to measure whether different resource management strategies within each sea-tenure regime had an impact on levels of household food security. In sum, demographic, spatial, economic, and nutritional data (among other potential data sets) can be analysed using a number of different approaches. For instance, Pollnac et al. [28] developed a number of MPAs success measures, which were analysed in relation to a number of independent variables categorized as contextual or project intervention factors, and then they used stepwise multiple regression to determine the most important predictors of success (e.g., levels of participation, decision making, and local population size, and so forth).

\subsubsection{Sea Tenure: Institutional Cognition and Governance.} When designing any kind of management program in Oceania, researchers and policy makers need to understand people's differences and similarities in territorial cognition, their cultural attitudes regarding interloping, good governance, resource conflicts (as a proxy for enforcement of access), and why people may or may not cooperate to protect their natural resources. That is, identifying how people understand their territorial rights (i.e., what is claimed, or property rights) and how this translates into an effective activation of those rights - that is, actual behaviour-through the control of participating members and exclusion of 
interlopers is crucial for understanding current management choices. Various methods can be used to understand these processes, including cultural consensus analysis, structured interviewing, and the use of experimental economic (e.g., public goods games) to provide information about group cohesion, conflict, and likelihood of cooperative behaviour. The aim is to understand the mental processes (i.e., cultural consensus) that inform, among other things, people's current governance and management decisions in local communities, so that successful resource management can be achieved.

Cognitive anthropological techniques are used to investigate the extent of shared knowledge among human communities or to understand the underlying assumptions that inform people's decisions [29]. Cultural consensus analysis, for instance, can be used to develop a cultural model utilized by people under different territorial regimes. Such methods can help to assess whether differences exist among people in their cultural perceptions regarding property rights and management strategies. In the Western Solomons, standard ethnographic methods of participant observation and informant interviews were paired with cognitive anthropological methods that included agreement questionnaires, free lists, and pile sorts [30]. Free listing generated lists of words pertaining to property rights that helped us to identify underlying ideas and notions about sea tenure. In the pile-sorting exercise, informants were given a set of cards inscribed with words in English and Roviana (which were formulated from the free-listing exercise), and they were asked to divide the cards into piles consisting of the most similar concepts. Final groupings were expected to reflect implicit classification elements for a specific cultural domain.

In the data analysis, we converted the survey results into an agree/disagree format and conducted a consensus analysis [30]. The results showed that informants, regardless of age, sex, education, and so forth, were using a single cognized model to answer the survey questions regarding sea tenure. However, cluster analysis of the pile sort data using nonmetric, multidimensional scaling (MDS) revealed that meaningful divergence in cognition existed between communities regarding population size, interloping, and overfishing. These differences, in turn, corresponded with people's notions of positive or negative capacity within each identified sea-tenure regime to manage marine resources (Aswani and Herman, unpublished data; [31]). Gelcich et al. [32] have also utilized an MDS technique to examine stakeholder perceptions following the establishment of comanagement regimes in coastal Chilean communities that already had informal CM systems. Simply put, this kind of information is fundamental for designing management (e.g., hybrid EBM$\mathrm{CM}$ ) regimes that account for inter- and intracommunity differences in institutional and environmental cognition.

Understanding community conflicts is fundamental for designing natural resource management. For instance, researchers need to identify whether or not conflicts over natural resources exist in a given area. Researchers can use simple ethnographic methods such as interview schedules and household questionnaires to understand conflicts between participants and between neighbouring communities. The questions can address conflicts among each estate's stakeholders, changes in use and access rules, modifications of boundary delineations, local mechanisms used to enforce management decisions, monitoring capabilities, traditional and legislative conflict-resolution mechanisms, and poaching incidence for each area (carried out by inclusive members or neighbouring groups). The interviews and questionnaires can also inquire about changes in the number of incidences of illegal fishing practices (as measured by fines levied, fishers caught, etc.).

Finally, grasping cooperative behaviour between stakeholders living in a given region is important for designing successful conservation programs. For example, what are the individual-level variables (e.g., age, sex, education, and ethnicity) and group-level variables (e.g., governance institutions, and group coercive action) that lead to cooperative behaviour for managing natural resources? Does ethnic diversity, for instance, enhance [33] or diminish [34] social cohesion and cooperation in public goods situations? And, more generally, what historical, economic, and political circumstances lead people to make greater contributions to public goods such as engaging in conservation projects? In order to gauge cooperative behaviour among stakeholders belonging to existing governance systems, a number of research methods can be used. For the Western Solomons, we used a simplified version of a voluntary contribution public goods game (PGG) from experimental economics. The game is designed, in part, to understand prosocial behaviour (or voluntary actions such as sharing that can benefit others or groups), and it examines people's behaviour when individual and group interests conflict with each other [35]. Preliminary results indicate that religious and ethnic homogeneity favoured prosocial behaviour among players in each village and that free-riding was more common in socially heterogeneous hamlets. Once more, this kind of information is essential for designating MPA and other kinds of management regimes.

2.1.4. Sea Tenure and Ecological Assessments. Current interdisciplinary studies are analyzing the relationship between changing customary (traditional) or semicustomary (hybrid or nascent) management systems and the status of artisanal fisheries [36, 37], food security and health [38], and the effects of introducing diverse fisheries management schemes $[13,39]$. This interest originates from the general failure of centralized and science-driven coastal fisheries programs in the Pacific region and a need to find alternative means of managing coastal marine resources. In the Western Solomons, we investigated the relationship between changing fishing intensity and management systems and the abundance of species that play a critical role in the resilience and vulnerability of coral reef ecosystems. Using a combination of marine science methods (see [40]), we investigated the ecological impact of localized subsistence and artisanal fishing pressure on parrotfish fisheries in Gizo Town (with weak sea tenure) in the Western Solomon Islands and used this information to conduct a comparative assessment of parrotfish abundance in open-access and customary closedaccess coral reefs in nearby Kinda and Nusa Hope villages (with functional sea tenure). The results suggested that the 
erosion of customary sea tenure is fostering the rapid decline of already vulnerable fisheries around urbanized regions of the Western Solomons and that functioning customary management systems, even with high population densities such as in the Kinda and Nusa Hope areas, can positively affect the management and conservation of parrotfish fisheries. Other studies $[37,41]$ have also utilized marine science to examine whether customary practices conserve resources, and this research generally suggests that they do.

2.2. Human Foraging Strategies. Researchers seldom identify human foraging strategies in a given region when designing marine conservation programs. Yet, it is indispensable to study fishing behaviour, including spatiotemporal human resource exploitation patterns (e.g., seasonal changes in fishing gear), human responses to variability in interand intrahabitat relative productivity (as determined by catch rates) and the influence of this variability on fishing strategies, and human threats to particular marine habitats. This information can help in the design of permanent and seasonal closures modelled in accordance with human seasonal foraging patterns. Simply stated, integrating fishing behavioural patterns into program design enhances people's compliance with conservation or any other form of fisheries management.

2.2.1. Human Behavioral Ecology and Fishing. Human behavioural ecologists have employed optimal foraging theory models to predict various aspects of human foraging behaviour. In the Western Solomons research, hypotheses drawn from the patch-choice model and the marginal value theorem (MVT) [42] were tested to study fishers' patch choices and time use across spatiotemporal variation. Predictions from these models were utilized to analyze the seasonal movements of fishers, to forecast the decisions that fishers make in the types and abundance of fish that they prey on, the use frequency of marine habitats, and the fluctuating intensification of fishing efforts. For example, when using the patch-choice model, the hypothesis that overall time allocation to a habitat type (set of patches) increases when seasonal productivity for that habitat increases and is higher than that of other habitats was tested. On the other hand, overall time allocation to a habitat type decreases when seasonal productivity for that set of patches declines and is lower than that of other habitats.

Researchers can use two related methods to test this hypothesis: focal follows and self-reporting diaries. First, focal follows involves keeping time-motion records for fishers and measuring their catches. The diary method consists of recruiting randomly selected subjects to keep diaries of their fishing activities. Through direct observations and self-reporting diaries, seasonal foraging data for a sustained period of 10 years (1994-2004), covering more than 10,000 foraging events and 15,000 hours of fishing activities, have been compiled in the Western Solomon case study. In Roviana and Vonavona, these data were used to explore the effects of village and habitat type on mean net return rates and fishing event duration. The mean net return rate measurement is equivalent to the energy gained during fishing (the kcal value of the edible catch) minus the labour input (labour costs incurred during foraging, including travel, search, and handling times) divided by the total residence time at a fishing ground.

In general, results showed that overall effort was directed to the habitats with the highest yields and that fishers moved between habitat types, fishing grounds, and species assemblages across different seasons to maximize their mean net return rate. More specifically, the results provided a better understanding of (1) the distribution of fishing methods and the geographical disparities in yield and effort, (2) different relative habitat productivities across seasonal and spatial variations, and (3) the changes in time use as a response to resource abundance or scarcity. Variance in fishing return rates and effort data for different habitats in regional villages not only showed differences in foraging strategies but also hinted at the effectiveness of each community's resourcemanagement strategies. The research generated data on local foraging patterns that aided in the MPA designation process. More generally, this type of research can help provide understanding of the strong interdependences between human foraging and the marine ecosystem, as well as possible environmental impacts of human activities-information that is vital for designing EBM or hybrid EBM-CM plans.

\subsubsection{Geographical Information Systems (GIS) and Human} Foraging. Socio-spatial information, such as artisanal fishing data, along with biophysical information can be incorporated into a GIS database for designing marine conservation programs (e.g., [43, 44]). In the Western Solomons case, human foraging strategies were distinctively conceptualized spatiotemporally by querying the GIS database and then displaying the data derived from the queries. The GIS was used to link the cartographic spatial data set of indigenously defined resource patches (615 sites collected with GPS receivers) with nonspatial attribute data (foraging data set). This allowed an analysis of the spatiotemporal relationships between particular marine habitats and the patches within them, on the one hand, and changes in their relative productivity and associated temporal increases or decreases in foraging effort by fishers of various regional villages to exploit these resources, on the other. More specifically, a query was run with the GIS that extracted the fishing events associated with each of the three locally recognized tidal seasons in the region (e.g., Roviana Lagoon). The visual representation of the foraging analysis made details more apparent and consequently gave a deeper understanding of intrahabitat variability and human responses to and strategies for dealing with this variability. In short, such knowledge can assist in designing marine conservation that is less disruptive to people's fishing strategies and, therefore, their livelihoods (see [45]).

2.3. Indigenous Ecological Knowledge. Scientists and policy makers are increasingly realizing the importance of incorporating indigenous ecological knowledge into inshore fisheries management (e.g., [46, 47]). Essentially, local 
fishers have first-hand experience and knowledge of the environment that they exploit, including knowledge about the direct assessment of local marine stocks and how they change over time, which is an expertise marine biologists rarely have. The value of local knowledge and practices for marine resource management is not just hypothetical because research has shown that marine protected areas that integrate IEK into their design can be successful biologically and socially $[13,22]$. In this sense, indigenous ecological knowledge can be very helpful for designing conservation programs.

2.3.1. GIS and Indigenous Ecological Knowledge. In the context of artisanal fisheries management, GIS coupled with ethnographic and marine science research has proven useful in delineating and cataloguing reefs belonging to the Miskito Indians in coastal Nicaragua [48], for mapping fishing spots in southeastern Brazil and helping local fishers use this knowledge to defend their territories from industrial trawlers [49], and for systematizing indigenous ecological knowledge into geospatial data to guide fishery management in Bang Saphan Bay, Thailand [50]. Socio-ecological and spatial analyses can be particularly useful for delimiting the fragmentation and distribution of locally identified habitats across a particular region. Habitat mapping is important for cataloguing habitat diversity and extent and for identifying sites that incorporate the ecological processes that support biodiversity, including the presence of exploitable species, vulnerable life stages, and interconnectivity among habitats for designing marine protected areas [51].

In the Western Solomons, we developed a reliable and participatory way to produce maps of the benthos and associated biological communities. First, we developed a qualitative definition of benthic communities, which incorporated both physical and biological characteristics [52], using an indigenous classification of benthic habitats commonly found in some of the areas targeted for conservation. Next, we employed a large format plotter to print a twofoot by four-foot hard-copy map of the planned MPA (with a scale of approximately $1: 3,500$ ). Five men and five women were selected to be the photo interpreters based on their knowledge of the marine environment and their fishing experience. The participants identified the main reefs and principal benthic characteristics and jointly drew the boundaries of abiotic and biotic substrates using a felttip marker directly on the photograph. The resulting paper map with the respective benthic types was scanned, and the image files were loaded into the GIS for georectification. After georeferencing, each of the boundaries was traced using on-screen digitizing techniques that created polygons (shape files) of each of the benthic substrates (Figure 1). This local information was ground-truthed through an actual underwater visual census conducted by local field assistants. Once the marine science data was logged into the GIS, we ran a spatial query that selected all of the points from the marine science survey layer found within each polygon of the indigenously defined, dominant benthic attributes, and we ran a point-to-point comparison for an accuracy assessment of indigenous ecological knowledge.
Thereafter, fishers were interviewed to map resident taxa and associated biological events of significance at each habitat type and to identify fishing areas within the boundaries of the proposed MPA sites. These interviews allowed for a better understanding of local conceptualization of the marine environment (Figure 2). Fishers guided us in a small boat around the perimeter of each named area and named and ranked (according to abundance) the presence and distribution of common fish species and the locations of spawning, nursery, burrowing, and aggregating sites for particular species within each recognized ground and associated benthic habitat. The spatial extent of the area (represented as polygons) and the location of particular biological characteristics (represented usually as points) were collected with Global Positioning System (GPS) receivers and imported into our GIS database as a layer. To ground-truth this information, we conducted visual counts through a static seven-minute fish survey from the surface at each site, during which the selected fish species were observed within a radius of five metres. Relative abundance measures were calculated for all species in each general habitat type to compare their distributions across the MPA regardless of habitat size (rough cover percentage). Finally, to determine whether the Baraulu participants were significantly better than chanceguessing at which fish species were present in which areas, fish observations were matched to local assessments through various methods detailed by Aswani and Lauer [53].

The analysis of both data sets showed that equivalence between indigenous aerial photo interpretations of dominant benthic substrates and in situ field dive surveys ranged between $75 \%$ and $85 \%$ for a moderately detailed classification scheme of the benthos, which included nine locally defined abiotic and biotic benthic classes for the MPA seabed. For the second analysis, the visual fish census showed a strong correspondence between the qualitative deductions of the local informants and the quantitative analysis of noncryptic species' general habitat distribution and relative abundance. In sum, this research showed the accuracy of local indigenous knowledge of dominant benthic substrates and specific resident taxa, and it also revealed that participatory engagements with local peoples can aid in successful implementation of MPAs, and, by extension, in the design of contextualized EBM plans.

\subsubsection{Indigenous Ecological Knowledge and Marine Science.} Indigenous ecological knowledge tied with current marine science knowledge can facilitate the identification of species and associated habitats that most urgently need protection. In Aswani and Hamilton [54], we wanted to assess the commensurability of indigenous ecological knowledge with marine science for identifying ecological processes that support biodiversity, including the presence of species with significant ecological functions, vulnerable life stages, and interconnectivity among populations of certain species. Three main aspects of Roviana indigenous ecological knowledge about bumphead parrotfish (Bolbometopon muricatum) were identified as being most relevant for management and conservation through a blend of marine science and 


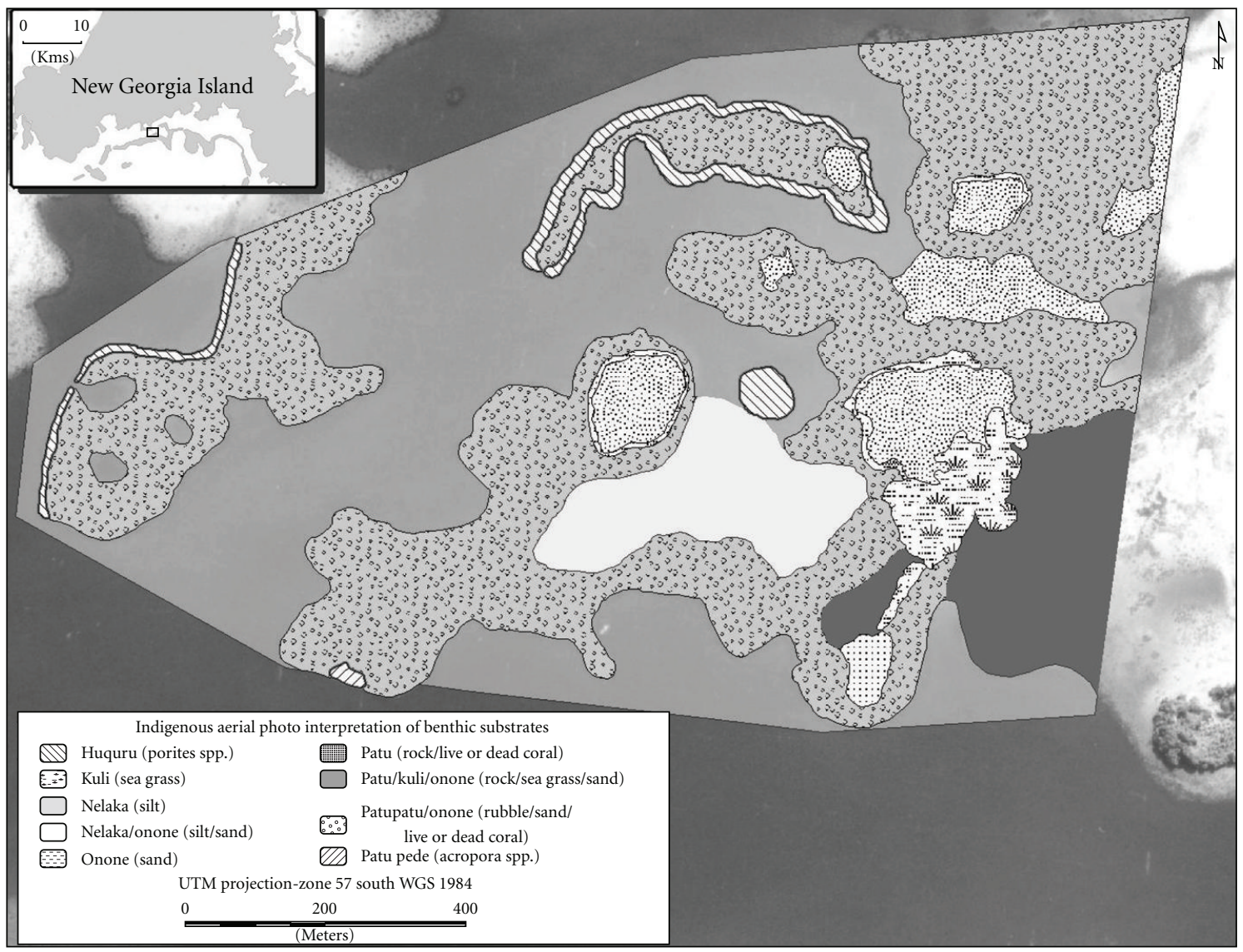

FIGURE 1: Informants' demarcation of predominant abiotic and biotic substrates on the aerial photographs of the Baraulu MPA, Roviana Lagoon [45].

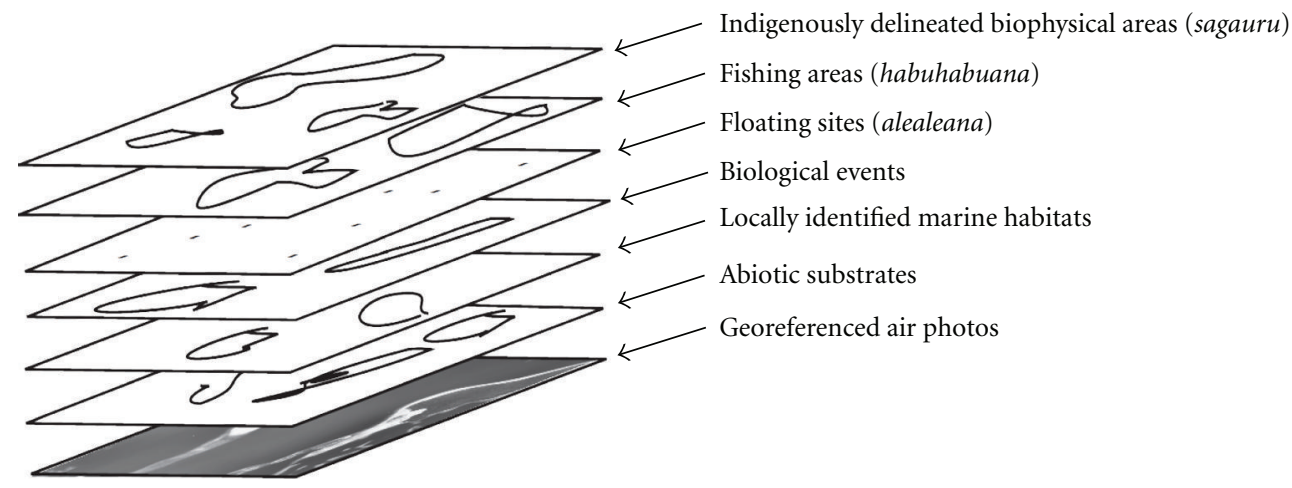

FIGURE 2: Indigenous hierarchical cognition of the seascape as represented by layers (or themes) in the GIS [45].

anthropological methods (e.g., interviews, creel surveys, and UVCs). We studied (1) local claims that fishing pressure has had a significant impact on bumphead parrotfish populations in the Roviana Lagoon, (2) the claim that only small bumphead parrotfish are ever seen or captured in the inner lagoon and that very small ones are restricted to specific, shallow, inner-lagoon nursery regions, and (3) the assertions made by local divers that bumphead parrotfish predominantly aggregate at night around the new moon period and that catches are highest at that time. Research results supported claims one and two, but did not support proposition number three.

Nevertheless, the results showed that in Roviana Lagoon, where many ecological and social changes have transpired within the lifespan of fishers, knowledge regarding ecological transformation can be detailed and useful. This research allowed for (1) verifying that the bumphead parrotfish is a species in urgent need of protection, (2) aiding in understanding how different habitats structure the size distribution of bumphead parrotfish, (3) helping in identifying 
sensitive locations and habitats that need protection, including shallow inner-lagoon sites that serve as nursery areas, and (4) becoming informed about how lunar periodicity affects bumphead parrotfish behaviour and catch rates. This information, in turn, allowed for the design of MPAs that integrated local knowledge with marine science-an approach that is of fundamental significance for designing hybrid CM and EBM plans.

2.4. Large-Scale Environmental Disruption and Socioecological Research. The long-term well-being of coastal populations is dependent upon coastal ecosystems and the critical economic and ecological services that they provide, including storm buffering and fisheries production. Yet the services provided by interface habitats are being degraded worldwide at an alarming rate [7]. This ecological degradation makes coastal populations increasingly vulnerable to massive environmental disruptions such as earthquakes and ensuing tsunamis. Researchers have suggested that rural populations with functioning customary/local management systems possess enough adaptive management qualities to make them more resilient (i.e., the capacity to absorb shock and transformation) to rapid environmental change (e.g., [55, 56]). Large-scale disturbances like hurricanes and tsunamis have provided researchers with an opportunity to evaluate, after the fact, if or how resilient those systems were to these disturbances.

On April 2, 2007, an earthquake measuring 8.1 struck the Western Solomons, which generated a tsunami that caused significant damage affecting both human and ecological communities. The scale of impact from the earthquake and tsunami varied greatly across different sites. In many villages this has caused a loss of the associated habitat biodiversity that previously supported a productive fishery-the basic source of household protein and income for communities of the region. For all the tragedy, this event offered our research team a unique opportunity to assess across this impact gradient the factors that may lead to the social, economic, health, and ecological resilience of coastal communities when they are faced with large-scale environmental disturbances. We asked the following. What are the socioeconomic, health, nutritional, and ecological consequences of catastrophic environmental events on coupled human and ecological systems? What are the human ecological responses (e.g., provisioning strategies) of coastal populations to environmental catastrophe? What social factors, such as cultural norms, property regimes, economic welfare, and regulatory enforcement, may lead to some communities being more socially resilient than others when faced with environmental disruption? And finally, do customary management systems increase the ecological and social resilience of coastal communities in the face of rapid change?

To answer these questions we are currently using a combination of interdisciplinary qualitative and quantitative research methods (many of which have been detailed in this paper) to (1) measure the socioeconomic effects of rapid and large-scale environmental disruption, (2) assess the concomitant responses of coupled human and ecological systems, and (3) evaluate potential drivers of system resilience across an impact gradient stretching from east to west in the Western Solomon Islands. In sum, resilience has long been recognized as an important component of effective resource management, but it has become increasingly important with the new emphasis on ecosystem-based management of marine systems. Our Western Solomons research program presents a good "before-and-after" experimental situation in which to measure the social and ecological vulnerability and resilience of coastal communities when faced by large environmental disturbances (as we have pre-earthquake social and ecological data for some affected communities). Grasping the human and natural responses to rapid ecological change is crucial to designing EBM plans and conserving marine ecosystems and associated services, particularly in the context of a changing climate and increasing human population [57].

2.5. Climate Change and Socioecological Research. Pacific Island communities are already experiencing the impacts of global and local climate change. They are especially susceptible to specific changes brought about by climate vulnerability (e.g., temperature variations, modifications of water flows and weather patterns, soil and water salinity or acidity, rain cycles, erosion, and coral bleaching). These changes have dramatically increased the levels of climatic unpredictability [58] and, consequently, the risks associated to the primary productivity and survival for coastal communities. Coastal communities are often also experiencing disproportionate levels of poverty, exposure to pollutants, or abusive external appropriation of the resources of their area. Climate change exacerbates the negative impacts of these marginalizing characteristics [59]. The possible socio-ecological adaptations associated to climate change may present multiple forms including environmentally driven migration, changes on the economic practices such as fishing and agriculture, forestry (e.g., intensification), institutional transformations, or new trading strategies $[60,61]$ —processes that can be measured using a wide range of social and natural science methods, some of which have been detailed in this paper.

Research on climate change is mostly done by physical or natural scientists. Socioecological research on climate change, however, affords research that measures the perceptions of local populations to the effects of climate change [62]. Social research on climate change combines scientific with the local perspectives on the issue. The advantage is that the local perspective allows researchers to gauge on the ground the social and ecological effects of an elusive macroscale phenomenon such as climate change. A local analysis is fundamental because climate change research requires the combination of diverse geographical scales (local, regional, international) and different levels of analysis.

Because social research in climate change lies at the intersection between scientific knowledge and local definitions of reality, an investigation requires the conceptual definitions of "change." Different social groups with different definitions of what is change or climate, for instance, are interacting in a dialogue that may result on important misunderstandings if there is no previous agreement on the meaning of the key concepts discussed. Currently, we are implementing a project 
in the Western Solomons designed to identify and analyze the local perception of "change" as well as measuring different local adaptations to such transformations. While we seek to identity transformations associated to climate change, our survey instruments are not designed around the concept of "climate change" but rather around any perceived changes around multiple dimensions of social and ecological reality. This is done to avoid a priori informant response bias and contamination (e.g., by information heard on the radio) [63].

Western Solomon communities are good candidates for climate change and adaptation research because (1) they are directly dependent on the environment and they still have a dominant subsistence economy (fishing and horticulture), (2) the environment they rely upon is fragile and fragmented and the different ecological patches of its landscape react differently to climate change, and (3) we have two decades of retrospective marine ecology and socioeconomic data. Local perceptions regarding climate change are being recorded through the use of various methods detailed in this paper (see, e.g., Section 2.1.3). Once compiled and analyzed, results of local perceptions will be matched against scientific studies (e.g., agricultural pests, lagoon hydrology) currently being conducted by our scientific team at the University of Queensland, Australia, to bring together the twin elements of traditional and scientific understandings for assessing the vulnerability of remote coastal communities living in the New Georgia Group, Western Solomon Islands. This will facilitate to fine-tune our resource management strategies (e.g., the current MPA network) to help local communities' better cope with environmental unpredictability associate to climate change.

\section{Discussion}

Environmental research and resource management plans that divide biophysical aspects of a system from social ones are inadequate $[55,56]$. Social and ecological systems are strongly coupled and highly complex, and they are changing rapidly, which places the social-ecological system at the centre of research that addresses the impacts of ecological change on human societies [64]. Today, methods for studying coupled human and natural systems are still being developed, and improving our conceptual framework and research methods for studying socio-ecological systems is fundamental to designing EBM. In addition, current studies ignore the role of individual actors in shaping the outcomes of coupled social-ecological systems-thus replicating the shortcomings of the ecosystems approach of the 1960s and 1970 s - and this needs to be corrected through the use of actor-based models if we are to understand socio-ecological systems and the actors within them [57].

In the case of the Pacific Islands, existing forms of customary management offer a significant socio-ecological context for hybridization with EBM. It is important to remember that customary management is not designed to conserve biodiversity but rather to allow participants to manipulate the environment for human benefit and well-being through various socially embedded management techniques (which may or may not be successful in resource management). In Oceania, there are a number of challenges in harmonizing EBM with CM systems, and simultaneously being in sync with provincial and national regulations and policies [65]. The first and most important step, however, is to integrate EBM with existing localized forms of customary management at ecologically and socially relevant scales [9]. There are a number of conceptual and operational principles that make these two systems of management actually amenable to hybridization.

First, indigenous people in the Pacific Islands conceptualize their territorial estates holistically, whereby they do not dichotomize land and marine spheres of ownership. Sea space and land space exist continuously, and indigenous cognitive categories do not dissociate these realms as westerners do [66]. Quintessential examples include the Hawaiian ahupua'a [67], the Fijian vanua [68], and the Marovo puava [17]. In Roviana, Western Solomons, people do not cognitively disassociate land and sea estates. The word pepeso literally means ground, but it is used as an inclusive property domain that is divided into four main zones: the mainland, the lagoon, the outer barrier islands and their adjacent sea-facing habitats, and the open sea. The ocean is then divided into named sites that represent biophysical resource exploitation areas, geomorphologic features that allow or obstruct people from navigating, cultural and historical markers that define the seascapes, areas of significant biological events (e.g., spawning aggregations), and areas nesting major and minor marine habitats (see [69]). This indigenous environmental cognition corresponds with one of EBM's core principles - the interconnectivity between and within terrestrial and marine ecosystems. The indigenous environmental conceptualization differs, however, in that it is embedded in indigenous sociocultural and religious practices in a way that EBM is not in Western society. Nevertheless, a holistic view of the environment is a first step towards reconciling these distinct world views.

Next, in many Pacific Island nations, islanders have exclusivity/excludability rights over their territorial states, and this allows for the implementation of many of EBM management tools, particularly limiting effort through a number of management strategies (e.g., taboo sites or de facto marine protected areas). Indigenous tenure rights identify particular users as having exclusive rights over resources and the ability to exclude nonmembers from accessing and using them. Rights of inclusiveness are distinguished via a number of sociocultural rules detailed previously. Entitlements, in any form, allow users access to a benefit stream while excluding nonmembers. The degree to which entitlement holders can exercise their territorial rights to exclude interlopers and punish inclusive members (thus managing their resources) varies from island to island and is often contingent upon the strength of traditional self-governance, population pressure, fishery commercialization, and a country's legal recognition of customary sea tenure, among other things [31]. Key here is that exclusive rights afford stakeholders the capacity to institute spatial, temporal, gear, effort, species, and catch restrictions [10], or tools that are fundamental in fisheries management and EBM. Inclusive stakeholders, therefore, can 
(1) protect vulnerable species and habitats (i.e., biodiversity and ecosystem function) and (2) protect susceptible life history stages (i.e., spawning and nursery grounds). In sum, tenure systems and associated customary management techniques, like EBM, can result in the protection of ecosystem structure and function, and they are place based, thus allowing stakeholders to restrict human activities that are detrimental to a local ecosystem.

Finally, as noted by Berkes [70, pages 17-18] customary management does not only entail ownership and use control of resources but a set of practices and perceptions that are embedded in the whole indigenous sociocultural, economic, and political systems. This socio-ecological system, therefore, nests (1) indigenous ecological knowledge of plants, animals, and the land- and seascape, (2) a resource management system in which IEK is put into practice to use and manage natural resources, (3) a set of social institutions such as customary sea tenure, which establishes the codes of social relationships between resource users and managers, and (4) a worldview that shapes environmental perceptions and gives meaning to the observed natural environment. The success of this integral system, in turn, is shaped by adaptive management, or the capacity of the system to change when faced with new social and environmental circumstances, and social learning, in which people learn about environmental uncertainty and feed this knowledge back into the management system. This is entirely in line with the core principles of EBM.

An essential objective of EBM is to integrate ecological, social, economic, and institutional perspectives, recognizing their strong interdependences [4]. Yet this aim has not been realized in actual management situations. Why, then, impose top-down, state-sponsored EBM plans in Pacific Island nations, when analogous management systems already exist in many parts of the region-especially systems that, as illustrated, share so much in common with EBM? In actuality, their similarities provide a fertile ground for the hybridization of traditional and modern environmental management systems. Note that this is relevant beyond Oceania, as localized systems of CM occur informally in many parts of the world, including the United States (e.g., [71]). In sum, if we are to cross-fertilize EBM and CM to create a holistic, hybrid management strategy, we need to identify, for both systems, the governance and management mechanisms at various spatial and temporal scales that result in positive institutional outcomes in terms of environmental sustainability, social equity, and institutional endurance.

EBM needs to resonate with local governance and ideational frameworks of references for its acceptance and integration with local systems of management. In the design of an MPA network in the Solomon Islands, my team and I selected MPA sites for their ecological and social value through a combination of local considerations and social and natural science research. Across many villages, traditional authorities and fishers in general agreed that an MPA neighbouring the village was the most feasible management strategy. Catch, size, and gear restrictions are difficult to enforce given certain cultural preferences and the extent of most sea territories, but the spotting of interlopers entering and exiting the MPA is not as difficult. Many sites were also selected through various research strategies detailed in this paper, including (1) an ethnographic study of regional customary sea tenure (CST) to assess, among other factors, the feasibility of implementing fisheries management in the area, (2) the incorporation of the visual assessments of local photo interpreters, who identified benthic habitats, resident taxa, and spatiotemporal events of biological significance, into a GIS database, (3) the coupling of indigenous ecological knowledge with marine science to study aspects of life history characteristics of vulnerable species, and (4) the incorporation of fishing time-series data (1994-2004) into the GIS to examine spatial and temporal patterns of human fishing effort and yields. The objective of the MPA network is to protect biodiversity and to sustain and improve ecological resilience in a cultural and socioeconomically viable fashion. This, in turn, will allow coastal communities to develop better responses to stochastic environmental events associated with global climate change, which invariably is what EBM fundamentally is.

\section{Conclusion}

This paper offers social and ecological scientists various integrated methods that transcend the false divide between the natural and social sciences, and it illustrates research approaches (among many) that integrate social and ecological analysis for studying human-environmental relations. The paper also illustrates how we can use these socioecological methods for conceptualizing natural resource management programs such as hybrid EBM and CM plans. From a local perspective, the systematic articulation of local ecological knowledge and cultural values through the natural (e.g., marine science) and social (e.g., anthropology) sciences can better promote local participation in the design and development of environmental management and produce a more inclusive approach to conservation. Community members in Oceania can better understand the biological value and the use restrictions of a management program when it builds upon local cultural practices with which the community members are familiar-a situation that facilitates rule enforcement and monitoring. Indeed, communitybased management and CM are not a panacea for current environmental and socioeconomic problems in the region, but they offer the only viable and socially just context for meaningful resource management. More generally, coupled studies of marine and social processes can foster management regimes that are more adaptive and effective and that move toward holistic, ecosystem-based marine conservation in the region.

\section{References}

[1] T. Pitcher, D. Kalikoski, G. Pramod, and K. Short, "Not honouring the code," Nature, vol. 457, no. 7230, pp. 658-659, 2009.

[2] E. K. Pikitch, C. Santora, E. A. Babcock et al., "Ecosystembased fishery management," Science, vol. 305, no. 5682, pp. 346-347, 2004. 
[3] P. Olsson, C. Folke, and T. P. Hughes, "Navigating the transition to ecosystem-based management of the Great Barrier Reef, Australia," Proceedings of the National Academy of Sciences of the United States of America, vol. 105, no. 28, pp. 9489-9494, 2008.

[4] J. Lubchenco and K. McLeod, Scientific consensus statement on marine ecosystem-based management. Document circulated for signature among marine scientists and then delivery to US ocean policymakers, 2005.

[5] K. E. Evans and T. Klinger, "Obstacles to bottom-up implementation of marine ecosystem management," Conservation Biology, vol. 22, no. 5, pp. 1135-1143, 2008.

[6] E. F. Granek, S. Polasky, C. V. Kappel et al., "Ecosystem services as a common language for coastal ecosystem-based management," Conservation Biology, vol. 24, no. 1, pp. $207-$ 216, 2010.

[7] E. B. Barbier, E. W. Koch, B. R. Silliman et al., "Coastal ecosystem-based management with nonlinear ecological functions and values," Science, vol. 319, no. 5861, pp. 321-323, 2008.

[8] B. Worm, E. B. Barbier, N. Beaumont et al., "Impacts of biodiversity loss on ocean ecosystem services," Science, vol. 314, no. 5800, pp. 787-790, 2006.

[9] P. Christie, R. B. Pollnac, E. G. Oracion, A. Sabonsolin, R. Diaz, and D. Pietri, "Back to basics: an empirical study demonstrating the importance of local-level dynamics for the success of tropical marine ecosystem-based management," Coastal Management, vol. 37, no. 3-4, pp. 349-373, 2009.

[10] J. Cinner and S. Aswani, "Integrating customary management into the modern conservation of coral reef fisheries in the Indo-Pacific," Biological Conservation, vol. 140, pp. 201-216, 2007.

[11] J. M. Brunnschweile, "The Shark Reef Marine Reserve: a marine tourism project in Fiji involving local communities," Journal of Sustainable Tourism, vol. 18, no. 1, pp. 29-42, 2010.

[12] P. Christie, D. L. Fluharty, A. T. White, L. Eisma-Osorio, and W. Jatulan, "Assessing the feasibility of ecosystem-based fisheries management in tropical contexts," Marine Policy, vol. 31, no. 3, pp. 239-250, 2007.

[13] S. Aswani, S. Albert, A. Sabetian, and T. Furusawa, "Customary management as precautionary and adaptive principles for protecting coral reefs in Oceania," Coral Reefs, vol. 26, no. 4, pp. 1009-1021, 2007.

[14] S. Aswani, "Common property models of sea tenure: a case study from the Roviana and Vonavona Lagoons, New Georgia, Solomon Islands," Human Ecology, vol. 27, no. 3, pp. 417-453, 1999.

[15] F. Toloa, R. Gillet, and M. Pelasio, "Traditional marine conservation in Tokelau. Can it be adapted to meet today's situation?" in Proceedings of the 23rd SPC Regional Technical Meeting on Fisheries, Noumea, New Caledonia, 1991.

[16] R. E. Johannes, Words of the Lagoon. Fishing and Marine Lore in the Palau District of Micronesia, University of California Press, Berkeley, Calif, USA, 1981.

[17] E. Hviding, Guardians of Marovo Lagoon: Practice, Place, and Politics in Maritime Melanesia, University of Hawaii Press, Honolulu, Hawaii, USA, 1996.

[18] K. Ruddle, "The context of policy design for existing community-based fisheries management systems in the Pacific Islands," Ocean and Coastal Management, vol. 40, no. 2-3, pp. 105-126, 1998.

[19] K. Ruddle and A. Satria, Eds., Managing Coastal and Inland Waters: Pre-existing Aquatic Management Systems in Southeast Asia, Springer, Heidelberg, Germany, 2010.
[20] S. Aswani, "Assessing the effects of changing demographic and consumption patterns on sea tenure regimes in the Roviana Lagoon, Solomon Islands," Ambio, vol. 31, no. 4, pp. 272-284, 2002.

[21] J. Cinner, "Socioeconomic factors influencing customary marine tenure in the Indo-Pacific," Ecology and Society, vol. 10, no. 1, article no. 36, 2005.

[22] R. E. Johannes, "The renaissance of community-based marine resource management in Oceania," Annual Review of Ecology and Systematics, vol. 33, pp. 317-340, 2002.

[23] R. Ohtsuka, "Subsistence ecology and carrying capacity in two Papua New Guinea populations," Journal of Biosocial Science, vol. 26, no. 3, pp. 395-407, 1994.

[24] M. Chun and K. Means, "Taking population into account in promoting conservation in Marovo Lagoon, Solomon Islands," SICDCD-WWF Report, 1997.

[25] S. M. Evans, M. E. Gill, A. S. W. Retraubun, J. Abrahamz, and J. Dangeubun, "Traditional management practices and the conservation of the gastropod (Trochus nilitocus) and fish stocks in the Maluku province (eastern Indonesia)," Fisheries Research, vol. 31, no. 1-2, pp. 83-91, 1997.

[26] A. W. Johnson, "Time allocation in a Machiguenga community," Ethnology, vol. 14, pp. 301-310, 1975.

[27] J. E. Cinner, S. G. Sutton, and T. G. Bond, "Socioeconomic thresholds that affect use of customary fisheries management tools," Conservation Biology, vol. 21, no. 6, pp. 1603-1611, 2007.

[28] R. B. Pollnac, B. R. Crawford, and M. L. G. Gorospe, "Discovering factors that influence the success of communitybased marine protected areas in the Visayas, Philippines," Ocean and Coastal Management, vol. 44, no. 11-12, pp. 683710, 2001.

[29] R. D'Andrade, The Development of Cognitive Anthropology, Cambridge University Press, Cambridge, UK, 1995.

[30] H. R. Bernard, Handbook of Methods in Cultural Anthropology, Altamira Press, Walnut Creek, Cali, USA, 2000.

[31] S. Aswani, "Customary sea tenure in Oceania as a case of rights-based fishery management: does it work?" Reviews in Fish Biology and Fisheries, vol. 15, no. 3, pp. 285-307, 2005.

[32] S. Gelcich, G. Edwards-Jones, M. J. Kaiser, and J. C. Castilla, "Co-management policy can reduce resilience in traditionally managed marine ecosystems," Ecosystems, vol. 9, no. 6, pp. 951-966, 2006.

[33] F. C. Santos, M. D. Santos, and J. M. Pacheco, "Social diversity promotes the emergence of cooperation in public goods games," Nature, vol. 454, no. 7201, pp. 213-216, 2008.

[34] J. Habyarimana, M. Humphreys, D. N. Posner, and J. M. Weinstein, "Why does ethnic diversity undermine public goods provision?" American Political Science Review, vol. 101, no. 4, pp. 709-725, 2007.

[35] J. Henrich, R. Boyd, S. Bowles et al., "“Economic man” in cross-cultural perspective: behavioral experiments in 15 smallscale societies," Behavioral and Brain Sciences, vol. 28, no. 6, pp. 795-815, 2005.

[36] R. A. Turner, A. Cakacaka, N. A. J. Graham et al., "Declining reliance on marine resources in remote South Pacific societies: ecological versus socio-economic drivers," Coral Reefs, vol. 26, no. 4, pp. 997-1008, 2007.

[37] J. E. Cinner, M. J. Marnane, and T. R. McClanahan, "Conservation and community benefits from traditional coral reef management at Ahus Island, Papua, New Guinea," Conservation Biology, vol. 19, pp. 1714-1723, 2005.

[38] S. Aswani and T. Furusawa, "Do marine protected areas affect human nutrition and health? A comparison between villages 
in Roviana, Solomon Islands," Coastal Management, vol. 35, no. 5, pp. 545-565, 2007.

[39] T. R. McClanahan and J. E. Cinner, "A framework for adaptive gear and ecosystem-based management in the artisanal coral reef fishery of Papua New Guinea," Aquatic Conservation: Marine and Freshwater Ecosystems, vol. 18, no. 5, pp. 493-507, 2008.

[40] S. Aswani and A. Sabetian, "Implications of urbanization for artisanal parrotfish fisheries in the Western Solomon islands," Conservation Biology, vol. 24, no. 2, pp. 520-530, 2010.

[41] T. R. McClanahan, M. J. Marnane, J. E. Cinner, and W. E. Kiene, "A comparison of marine protected areas and alternative approaches to coral reef management," Current Biology, vol. 16, no. 14, pp. 1408-1413, 2006.

[42] D. W. Stephens and J. R. Krebs, Foraging Theory, Princeton University Press, Princeton, NJ, USA, 1986.

[43] R. Bates and B. James, "Marine GIS for management of Scottish marine special areas of conservation," in Marine Geography: FIS for the Oceans and Seas, J. Breman, Ed., ESRI Press, Redlands, Calif, USA, 2002.

[44] P. J. Mumby, P. S. Raines, D. A. Gray, and J. P. Gibson, "Geographic information systems: a tool for integrated coastal zone management in Belize," Coastal Management, vol. 23, no. 2, pp. 111-121, 1995.

[45] S. Aswani and M. Lauer, “Incorporating fishermen's local knowledge and behavior into geographical information systems (GIS) for designing marine protected areas in Oceania," Human Organization, vol. 65, no. 1, pp. 81-102, 2006.

[46] J. M. Acheson and J. A. Wilson, "Order out of chaos: the case for parametric fisheries management," American Anthropologist, vol. 98, no. 3, pp. 579-594, 1996.

[47] F. Berkes, J. Colding, and C. Folke, "Rediscovery of traditional ecological knowledge as adaptive management," Ecological Applications, vol. 10, no. 5, pp. 1251-1262, 2000.

[48] B. Nietschmann, "Defending the Miskito reefs with maps and GPS: mapping with sail, SCUBA, and satellite," Cultural Survival Quarterly, vol. 18, pp. 34-36, 1995.

[49] A. Begossi, "Mapping spots: fishing areas or territories among islanders of the Atlantic forest (Brazil)," Regional Environmental Change, vol. 2, pp. 1-12, 2001.

[50] S. Anuchiracheeva, H. Demaine, G. P. Shivakoti, and K. Ruddle, "Systematizing local knowledge using GIS: fisheries management in Bang Saphan Bay, Thailand," Ocean and Coastal Management, vol. 46, no. 11-12, pp. 1049-1068, 2003.

[51] T. Stevens and R. M. Connolly, "Testing the utility of abiotic surrogates for marine habitat mapping at scales relevant to management," Biological Conservation, vol. 119, no. 3, pp. 351-362, 2004.

[52] R. J. Diaz, M. Solan, and R. M. Valente, "A review of approaches for classifying benthic habitats and evaluating habitat quality," Journal of Environmental Management, vol. 73, no. 3, pp. 165-181, 2004.

[53] S. Aswani and M. Lauer, "Benthic mapping using local aerial photo interpretation and resident taxa inventories for designing marine protected areas," Environmental Conservation, vol. 33, no. 3, pp. 263-273, 2006.

[54] S. Aswani and R. J. Hamilton, "Integrating indigenous ecological knowledge and customary sea tenure with marine and social science for conservation of bumphead parrotfish (Bolbometopon muricatum) in the Roviana Lagoon, Solomon Islands," Environmental Conservation, vol. 31, no. 1, pp. 69-83, 2004.
[55] C. Folke, T. Hahn, P. Olsson, and J. Norberg, "Adaptive governance of social-ecological systems," Annual Review of Environment and Resources, vol. 30, pp. 441-473, 2005.

[56] F. Berkes, J. Colding, and C. Folke, Navigating SocialEcological Systems: Building Resilience for Complexity and Change, Cambridge University Press, Cambridge, UK, 2003.

[57] S. Aswani et al., "Understanding socio-ecological impacts and responses to large scale environmental disturbance in the Western Solomon Islands," University of California Santa Barbara and San Diego State University unpublished document.

[58] J. Barnett, "Adapting to climate change in Pacific Island countries: the problem of uncertainty," World Development, vol. 29, no. 6, pp. 977-993, 2001.

[59] S. Crate and M. Nuttall, Eds., Anthropology and Climate Change: From Encounters to Actions, Left Coast Press, Walnut Cree, Calif, USA, 2009.

[60] M. Cooper, "Turbulent worlds: financial markets and environmental crisis," Theory, Culture and Society, vol. 27, no. 2, pp. 167-190, 2010.

[61] W. N. Adger, "Social capital, collective action, and adaptation to climate change," Economic Geography, vol. 79, no. 4, pp. 387-404, 2003.

[62] C. Roncoli, T. Crane, and B. Orlove, "Fielding Climate Change: The Role of Anthropology," in Anthropology and Climate Change: From Encounters to Actions, S. Crate and M. Nuttall, Eds., Left Coast Press, Walnut Cree, Calif, USA, 2009.

[63] I. Vaccaro and S. Aswani, "Building socioecological resilience to climate change in the Western Solomon Islands," University of California Santa Barbara unpublished document.

[64] J. Liu, T. Dietz, S. R. Carpenter et al., "Complexity of coupled human and natural systems," Science, vol. 317 , no. 5844, pp. 1513-1516, 2007.

[65] R. Pomeroy, L. Garces, M. Pido, and G. Silvestre, "Ecosystembased fisheries management in small-scale tropical marine fisheries: emerging models of governance arrangements in the Philippines," Marine Policy, vol. 34, no. 2, pp. 298-308, 2010.

[66] G. Klee, Ed., World System of Traditional Resource Management, V. H. Winston and Sons, New York, NY, USA, 1980.

[67] N. Meller and R. H. Horwitz, "Hawaii: Themes in land monopoly," in Land Tenure in the Pacific, C. Crocombe, Ed., pp. 25-44, University of the South Pacific, Suva, Fiji, 1987.

[68] A. Ravuvu, Vaka i Taukei: The Fijian Way of Life, Institute of Pacific Studies, University of South Pacific, Suva, Fiji, 1983.

[69] S. Aswani and I. Vaccaro, "Lagoon ecology and social strategies: habitat diversity and ethnobiology," Human Ecology, vol. 36, no. 3, pp. 325-341, 2008.

[70] F. Berkes, Sacred Ecology, Routledge, New York, NY, USA, 2008.

[71] J. Acheson, Capturing the Commons: Devising Institutions to Manage the Maine Lobster Industry, University Press of New England, Hanover, NH, USA, 2003. 

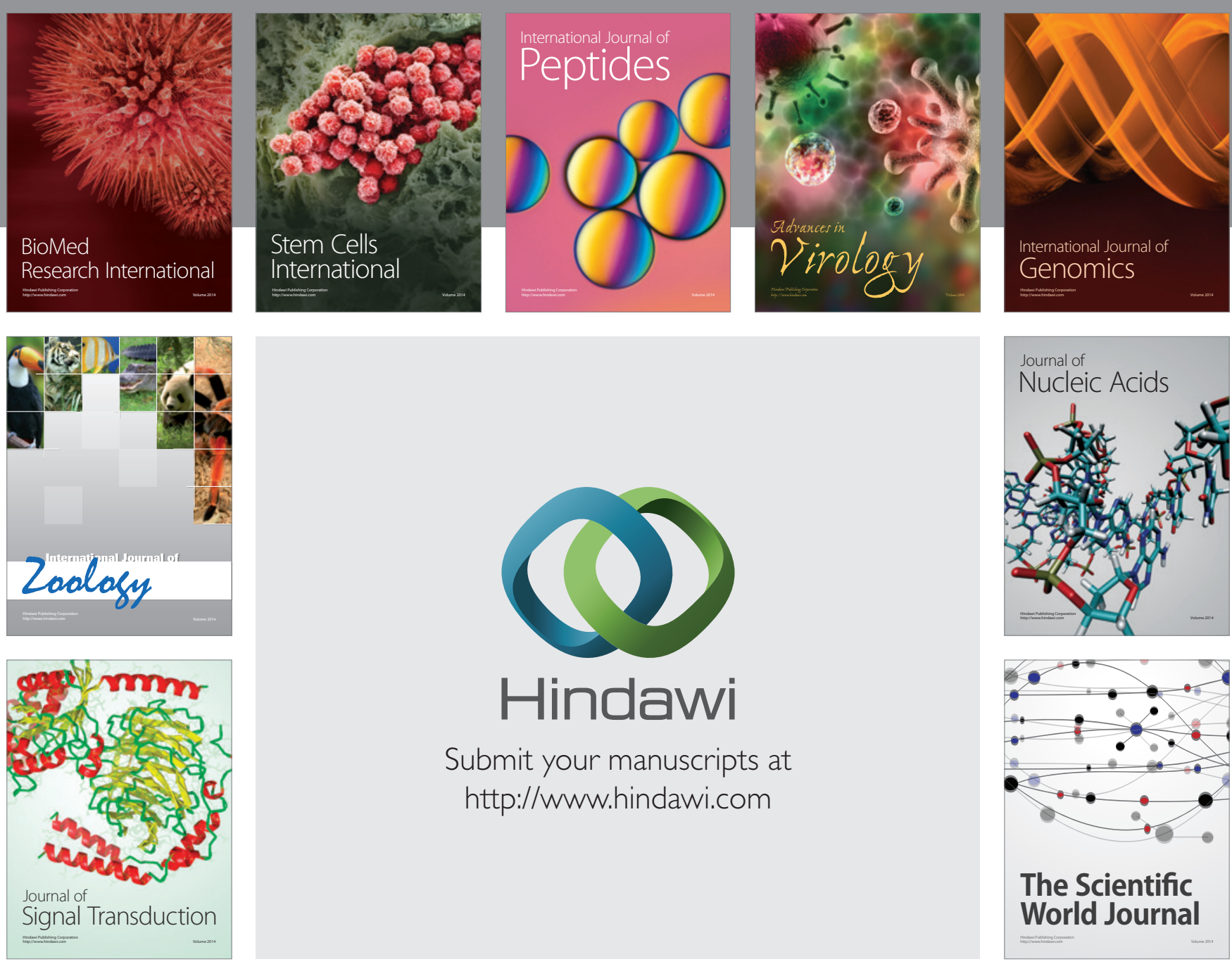

Submit your manuscripts at

http://www.hindawi.com
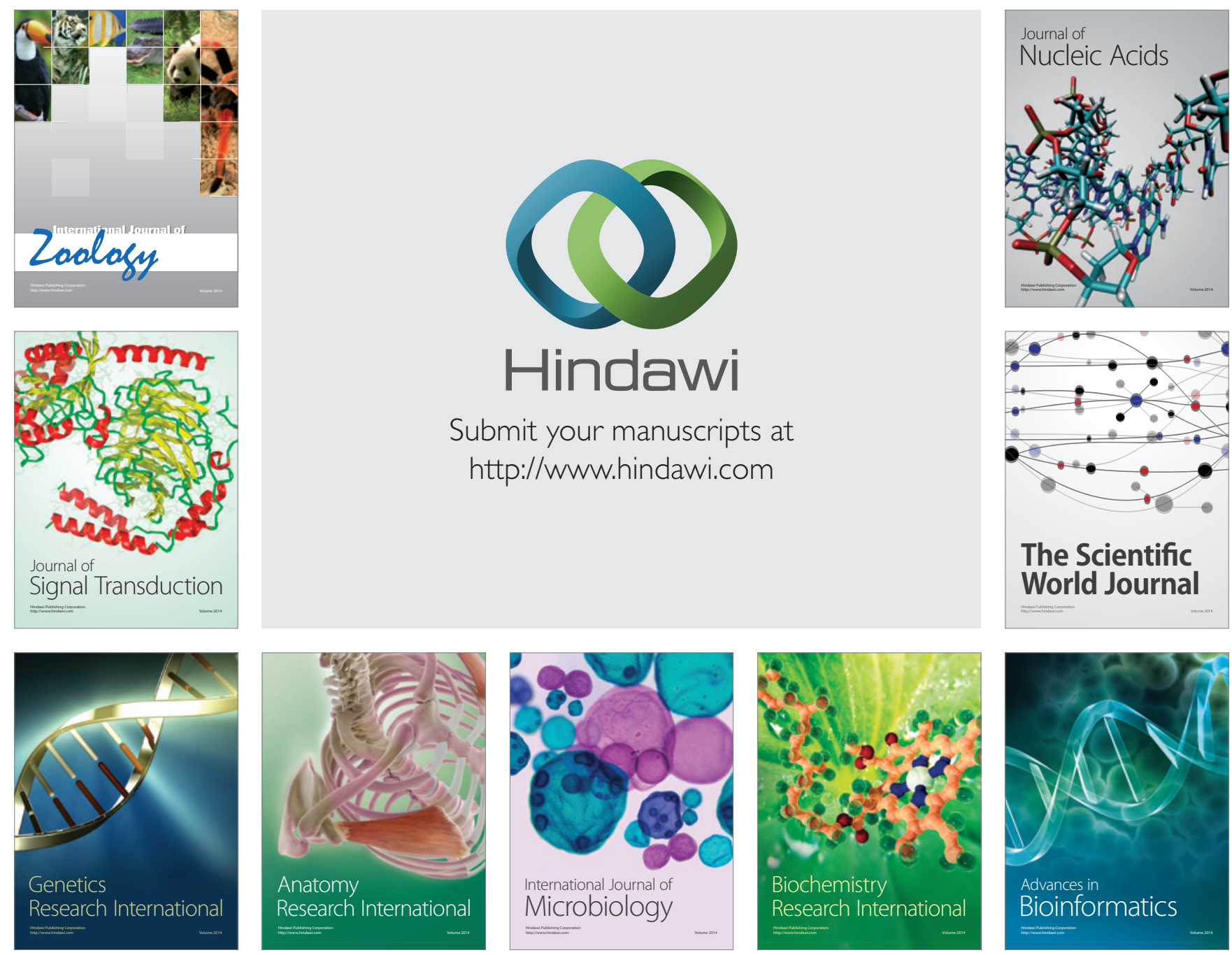

The Scientific World Journal
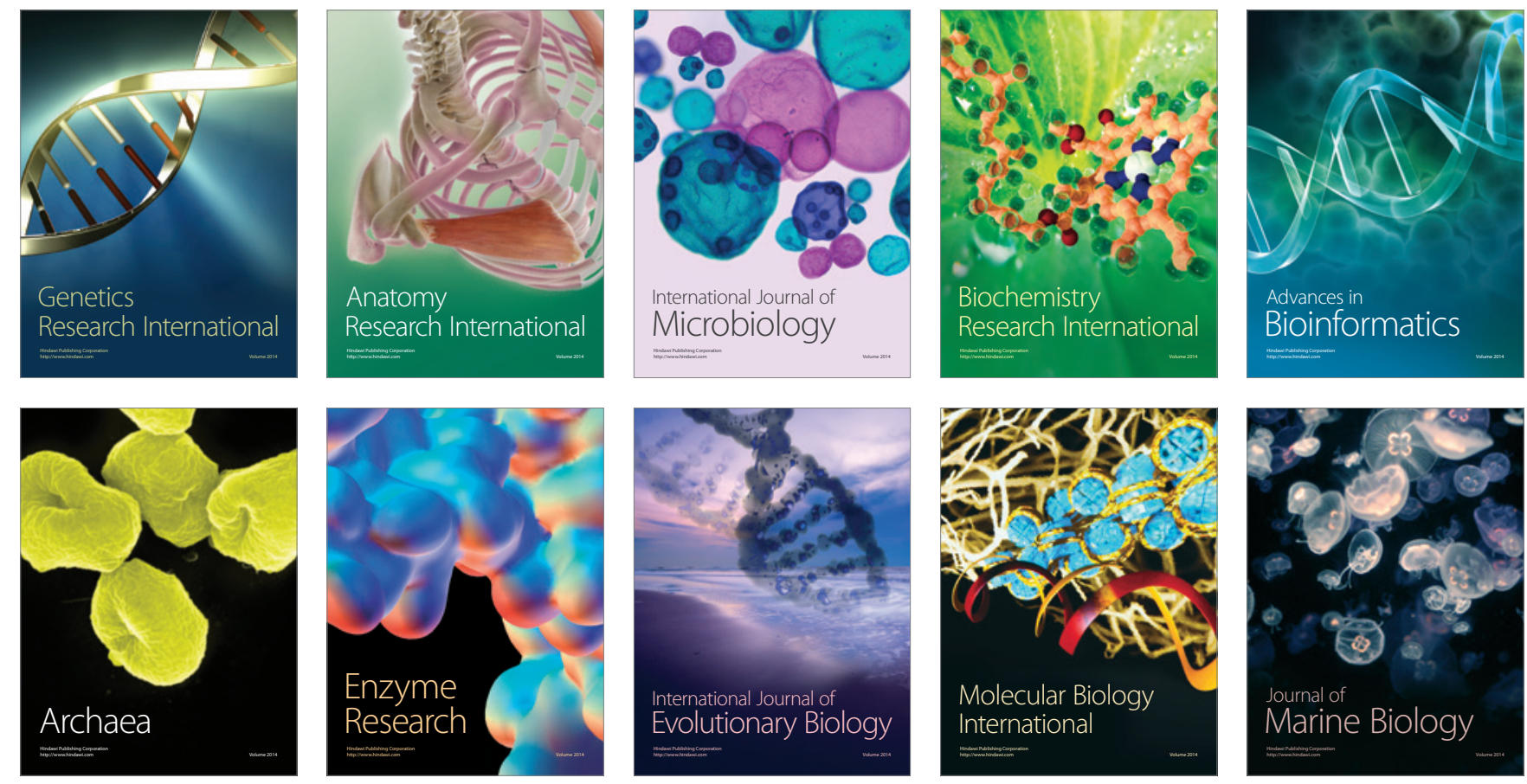